\title{
Teaching English language to young school-age children while making projects, playing games and using robotics
}

\author{
Vera A. Rozhina - Tatiana A. Baklashova
}

DOI: 10.18355/XL.2018.11.01.10

\begin{abstract}
The aim of the article is to identify the most effective methods of teaching English to young schoolchildren and the possibilities of using robotics in primary school. Today, robotics classes are the most popular direction in the field of additional education, they are mainly related to the development of engineering thinking, mastering the basics of design and programming and career guidance. The use of robots as a means of teaching English to 6-10 year old children in the Russian secondary school hasn't been studied well enough. It is characterized by the novelty of the subject of discussion, the lack of scientifically based programs and teaching materials, the shortage of teachers who are able to implement in practice-wide possibilities of educational robotics for experimental verification of our hypothesis. The article presents the main methods which help to develop the highest communicative skills of young schoolchildren, problems in teaching English language to children and ways of their solution. The authors of the article offer to use robotics, project and playing activity of schoolchildren at English lessons and in extracurricular activity as a means of teaching English in elementary school. The article is of practical value for English teachers who work with 6-10 year old children.
\end{abstract}

Key words: English language teaching, young school-age schoolchildren, project activity, educational robotics

\section{Introduction}

\section{Relevance of the problem}

At present English is one of the most popular languages in the world, it is spoken by 1.5 billion people, and another 1 billion people are studying it. It should be noted that according to the research (Efimenko, 2016), our country is the 39th among 70 states which are included in the English language proficiency rating compiled by EF (Education First). Russia is between Ecuador and Mexico, i.e., it is in the group with a very low level of English. It means Russian education institutions do not have a very high level of teaching English.

Therefore, according to the Federal state educational standards of Russia (Decree, 2009), one of the important tasks of modern education is to teach English to children from the age of 7 and to significantly increase the level of English of schoolchildren. Foreign culture is a part of the world culture. The knowledge of at least one foreign language by school graduates will help to solve some problems of the development of our society and to occupy a full place in the world community. Moreover, studying a foreign language and knowing a foreign culture makes a significant contribution to the formation of the personality of children (Rogova, Vereshchagina, 2012). After all, Aristotle said that you are so many times a person, how many languages you know.

Thinking and speech of a person develop especially intensively in childhood. Children of 6-10 years perceive a foreign language subconsciously. Languages at this age are much more easily absorbed than later. Children understand the situation much faster than speaking in English on this topic (Kunbuttaeva, 2017). Children of young school age have an excellent involuntary memory, besides their arbitrary and long-term memory develops successfully as well as methods of thinking and remembering. All these factors create favorable conditions for mastering a foreign language. 
The boom in the development and production of robots in the last decade has attracted the attention of the public, educators, and parents. Robotics penetrates more and more into the sphere of education: in Russia, there are numerous clubs of robotics in the centers of additional education; there are different programming courses (coding) abroad and engineering design in school curricula (Eguchi, 2014). Numerous studies (Papert, Harel, 1991; Saatcioğlu, Boru, 2015; Galushkin, 2015) underline the positive role of educational robotics in developing creative abilities, engineering thinking, metacognitive skills, readiness for cooperation and implementation of project activities.

\section{Goals and objectives of the study}

The purpose of this article is to identify effective methods and tools for teaching English to 6-10-year-old children. The main tasks of the research are: to study the content and methods of teaching English to young schoolchildren, summarize the positive experience of using the project method in the process of mastering foreign language competencies, develop a program for playing young schoolchildren in English, analyze educational capabilities of robotics, develop educational situations using robotics.

\section{Literature Review}

\section{Analysis of Russian scientific and pedagogical literature}

The relevance of the problem of learning English is described by many Russian scholars, especially the importance of a foreign language for the development of the Russian socio-cultural environment is underlined by N.V. Efimenko (2016), I.E. Shkabara \& V.I. Rapygina (2016). The problems of teaching English to children are studied by many teachers. Science offers various methods of teaching a foreign language to children of young school age. Methods of teaching through play activity are described by E.V. Bodrova (2014). N.S. Alekseeva (2013) and N.A. Kiseleva (2015) describe psychological aspects of the influence of play activity in the process of teaching English to young schoolchildren.

Along with the methodology of teaching through playing, the author offers to learn through project activities. The importance of these techniques and their effectiveness is considered in works of V.I. Mezenina (2016), N.A. Balakina (2016).

L.V. Perevozchikova (2015) in her work describes the psychology of creativity. The work deals with the linguistic aspects of teaching English, such as the development of speech abilities, phonemic hearing, the ability to imitate, to distinguish foreign sounds by hearing, to the logical presentation of one's thoughts. And also mental functions, which are associated with speech activity in the application of role-playing game, are developed,

A.A. Mirolubova (2010) and N.B. Rumyantseva (2006) reveal in their works teaching methods for schoolchildren which offer a selection of didactic material and a system of verbal assignments focused on the educational and communicative outcome.

In general, all authors note that the younger a child is, the more likely he can master the second language. If the native language is formed in time and correctly, the mastering of the second language is very beneficial for the intellectual development of the child.

The concept and essence of educational robotics are explored in I.V. Tuzikova's (2013) article. In the collection of methodical recommendations, Koryagin and Smolyaninova (2016) give practical assignments for mastering LEGO WeDo. Robotics as a means of teaching and development of young schoolchildren is discussed in N.V. Yanikova's (2015) article, which links robotics with the organization of children's project activities. The educational-methodical manual

XLinguae, Volume 11 Issue 1, January 2018, ISSN 1337-8384, eISSN 2453-711X 
(Ryndak, Dzhenzher, Denisova, 2009) is similar; it includes recommendations for organizing project activities in the Scratch programming environment. It presents planning of classes, covering 26 themes of the cognitive and creative direction and offers the approximate thematic planning of the extra-curricular project scientific and cognitive activity of the young schoolchild. D.V. Andreev (2015) and V.L. Sinebryukhova and A.T. Mamedova (2015) justify the role of the robotics course in the development of the motivation of teaching young schoolchildren. The issue of using robotics for teaching English has not been studied enough.

\section{Analysis of foreign studies}

It is necessary to note a high degree of elaboration of methods of teaching English to children of young school age in the works of foreign teachers. Methods of creative teaching based on play activities are widely covered in works of R.S. Mansfield \& T.V. Busse (1981). They have revealed psychological factors that influence the subconscious assimilation of lexical material in games.

A. Groot and H. Comijs (1995) consider in their works features studying the second language in early school-age. They describe the use of language immersion in school conditions in details. In the classroom, schoolchildren apply their language abilities in real life conditions and can freely express their thoughts in a foreign language using appropriate grammatical rules. During classes, schoolchildren and teachers do not speak their native language. Everything is explained with the help of already familiar phrases and lexical constructions, as well as mimicry, gestures, audio recordings, visual material.

R. Aitken (2002) on the basis of research practices proposes to use the language teaching method in the conditions of school education through a dialogue of teachers working with children of young school age. Such training is built on the close interaction of the teacher and children in the process of communication in order to achieve a common goal through communication, the ability to express their thoughts in various ways. As a result of this interaction, the communicative level of one participant is expanded by communicating with other participants.

The use of educational robotics attracts the attention of researchers abroad. However, it should be noted that most publications are related to humanoid robots that are designed to replace the teacher or student in the educational process. For example, N.A. Aidinlou et al. (2014) have studied the positive effect of interactive communication with robots NAO (a robot-teacher, which is capable of voice communication with children), Tiro (a teacher's assistant, which is able to play and learn poems, songs and dances with children, make riddles or show lesson goals, transfer images to TV ), and Robovie, Nimo (also assistant teachers), Papero robot (can play rock-scissors-paper game), (a robot-apprentice, communication partner), VGO (a telepresence robot which helps a disabled child to virtually be present in class, to participate in his life through network) in foreign language lessons and in after-hours activities. The problem of introducing robotics as a separate subject in the curriculum of schools is considered in the works of A. Eguchi (2014). Specifics of designing and programming robots in childhood are analyzed by A. Sullivan and M.U. Bers (2015). E. Hyun et al. (2008) compare learning a foreign language with a robot with artificial intelligence and using multimedia, and the talking robot definitely wins. S. Lee et al. (2010) have evaluated the cognitive effect of the robot on the development of children's oral skills, for example, the clarity of pronunciation of sounds). S. Papert and I. Harel (1991) have repeatedly investigated the results of the speech development of preschool and primary school children in the process of constructing robots LEGO Education WeDo.

Thus, the problem of teaching English is related to the organization of an optimal foreign language environment for immersing children both in foreign language lessons and outside it, as well as providing the learning process with all the necessary 
materials and interactive means. Foreign sources show the positive impact of robots on learning a foreign language.

\section{Methodology}

\section{Project method in teaching English}

Not every young schoolchild in Russia has a real opportunity to use his or her knowledge of English every day. Project method helps to solve this problem; it is well used in studying any topic of the school program, both individually and in groups. In the process of work on the assignment, the project group joins the unified activity, so that it becomes possible to create the necessary conditions in order to develop independence, creative activity, the emotional sphere of the pupils, and train personal and collective responsibility. Working on the project, schoolchildren learn to use acquired knowledge in practice, their interest in foreign language increases. With the systematic use of project activities, the motivation and the effectiveness of training significantly increase (Mezenina, 2016).

While forming analog support, an important auxiliary factor is a possibility of reconstructing, albeit an artificial, but the same general algorithm for the perception and assimilation of a language that has been implanted in the human consciousness since childhood. We believe that the main significance of this algorithm is the connection of the widest form of perception. Therefore, it should be noted that in general, children's perception is characterized by substantial thematic and age selectivity. It refers to focusing on specific types of information and the ability to retain this information in operative and long-term memory, which is very important for learning the language, and for the child's organic need to change periods of perception of new information, including language, with relaxation and switching on the main activity. In this case, successful assimilation occurs more fully if it is supported by both sensory and emotional perception and the proper context in the situation (Balakina, 2016).

Project activities in a foreign language can be organized as joint voluntary actions, as well as the implementation of socially important projects. The teacher of English has the opportunity to attract a large number of students to the project activity, having formed them into groups to work on a certain topic, the group also has the opportunity to choose the topic independently. Each of the students, working in a team, is responsible for a particular type of activity: material search, drawing, the creation of slides. The team forms each stage of the project and decides on the method of its presentation in the general discussion. The advantage of a foreign language as an academic discipline in a particular case is the availability of the possibility of learning in the process of working on projects even at the initial stage of learning English. If at the beginning simple topics are studied, such as: "My house," "My school," then later they are more complex: "My city," "Environmental problems," "Garbage processing in Russia and the USA" and others depending on the interests of students. It should be noted that the project work is an obligatory part of the educational program for studying a foreign language in a modern school (Alekseeva, 2013).

The original presentation of the material by the teacher and the ability to achieve the goal contributes to the creative development and formation of the language competence of the students. Moreover, it forms a generation with non-standard thinking and the ability to independently find optimal solutions in any life situation.

\section{Game method and contextual approach}

One of the effective and universal methods of teaching is the game that creates comfortable psychological atmosphere and helps to imitate the natural language environment. Games that are used in class can serve to form speech, lexical,

XLinguae, Volume 11 Issue 1, January 2018, ISSN 1337-8384, eISSN 2453-711X 
grammatical, phonetic, spelling skills, and also have a creative function that develops colloquial practice. Among the important results of this activity, we can note the development of communicative abilities of students, the development of cognitive, emotional and volitional spheres, as well as the expansion of the general linguistic outlook (Bodrova, 2014).

The contextual approach is the base of one of the programs for teaching English to young schoolchildren. Let us consider a thematic course (36 hours) "Pirate English," which is designed for 8-year-old children for nine weeks of study in the first quarter of the academic year. Consideration of learning through games in our concept is implemented as a method that will allow children to make sense of new language material, relying on a specific behavioral stamp (Vozlomitel, 2016). In fact, the material of the study is not the standard adapted educational texts and dialogues, but children's play discourse. Within the framework of frames and scenarios, lexical and grammatical models are consolidated, and the experience of communication is accumulated (Tannen, 1993; Howarth, 2000). It is significant that the perception of new material by children occurs in the course of live game communication, which makes it possible to quickly remove some factors that negatively affect the learning of a foreign language - excitement and emotional tension, and the formation of authentic speech behavior. The program has a clearly defined sequence of educational-role situations, focused on mastering certain lexical thematic blocks (Groot, 2002). These blocks, due to a common thematic unity, serve each other as a support and help to consolidate in children's memory a systemic semantic whole, which, for example, is represented in a "pirate" context by several micro themes: "Weather", "Naval navigation and Ground", "Equipment of the ship", "Geographical names", "Pirate clothes", "Arms and its varieties", etc. Realization of "an active" contextual impact on children is carried out through functional topics attributes, based on the visual perception - pictures, maps, symbols or logos, video clips. Also very important is the auditory perception (pirate songs, rhymes, commands). Tactile sensations are also very important - fragments of the game with the use of pirate attributes, clothes, toys. Here the perception of the situation matters (Ullmann, 1967).

Theatrical performances, learning songs and poems play a crucial role in the formation of lexical and phonetic skills, and stimulates the achievement of both personal and meta-subject results: increase in the overall cultural level, development of artistic imagination, formation of the ability to interact with the surrounding reality when performing various actions in limits of speech needs and opportunities (Perevozchikova, 2015).

The proposed context includes a language level with speech greeting models, ship commands, ship log structure, captain's dialogues with sailors, etc., as well as the distribution of key roles of various kinds: search of treasures using a map; pirate maneuvers, etc.

The main thematic word is particularly important in the process of presentation and further consolidation of the material. The work with it is carried out in a sequence that is already familiar to schoolchildren: a) beginning; b) repeated repetition in the group and individually, c) repetition in musical accompaniment; d) pronunciation and spelling; e) fixing the image through thematic attributes; e) mastering of the keyword or expressions in different lexical and grammatical constructions. Let's demonstrate it using the lexeme 'sail':

a) initial introduction takes place through the display of images of ships with sails;

б) repeated repetition of the lexeme in numbers;

в) repetition in music 'let set sails, let set sails';

г) phonetic, and then graphical perception and reproduction in notebooks and onboard log: 'we are ready to set sails';

д) consolidation of success by means of an illustration in an onboard log, a game with a model of a pirate ship, a raft; 
e) working out of the main word and expression through the following lexical and grammatical models (Mansfield, Busse, 1981):

- a black/ white sail/, a big/ small sail, a makeshift sail, a lowermost sail, a slack sail;

- this/that/the sail;

- one/two/three/four sail(s);

- the mast and sails;

- under the sail, on the sail;

- to set/raise/lower sails,

- sail the high seas, sail on;

- a young / old / sad /happy / clean / dirty / short / tall / thin / round / brave / novice / gruesome

sailor;

- a sailor hat ragged sailor clothes;

- long/ short sailing;

- a sailing boat/ black sailing ships

\section{Application of educational robotics in teaching English}

Educational robotics is a very broad term that combines several interrelated activities (design, modeling, electronics, programming, prototyping, etc.), training programs, robot design kits, educational materials and pedagogical concepts related to the use of robots for educational purposes (Eguchi, 2014). Educational robotics is also a new interdisciplinary direction for schoolchildren (Tuzikova, 2013), integrating knowledge from physics, drawing, mechatronics, technology, mathematics, natural sciences, cybernetics and computer science, providing a base for systemic thinking and allowing students to be involved in the process of engineering creativity. In our understanding, educational robotics in an elementary school is a unique learning tool that helps to form an educational environment that is attractive for children with practically meaningful and entertaining activity products that reinforce students' interest in the studied subjects and develop their abilities.

The pedagogical literature has repeatedly revealed the importance and possibilities of educational robotics in the development of logical and symbolic educational activities of young schoolchildren, their algorithmic and engineering thinking, fine motor skills, ICT competence, ability to retain the educational task, plan and reflect their actions, follow instructions, design and research skills, abilities to formulate and solve problems, teamwork skills, subject knowledge and skills in mathematics, technology and the environment, personal qualities, which meet the needs of modern society. (Kor'agin, Smolyaninova, 2016; Papert, Harel, 1991; Sinebryukhova, Mamedova, 2015). The role of using educational robotics in stimulating the educational motivation of younger schoolchildren is also emphasized (Sinebryukhova, Mamedova, 2015). When working with a robot constructor, the pupil sees the results of his work and has the opportunity to apply the knowledge gained in practice, thus eliminating the discrepancy between the better-developed in the 1-2 grades visualimaginative thinking that requires the constant presence of visualization in the lesson and the abstract nature of the information presented to the pupil at school. A real physical object - a robot - serves as a visual aid and an instrument for experimentation.

In recent decades, a large number of robotic kits for primary and secondary schools have been launched: LEGO Education WeDo and LEGO Mindstorms Education (Denmark), Fischertechnik Computing (Germany), Aldebaran NAO (France), Robots in Schools EDBOT (UK / Korea), Robotis Bioloid (Korea), RoboThink (USA), Modular Robotics Cubelets (USA), Modular Robotics Cubelets (China), etc. In Russia, LEGO WeDo 2.0, LEGO Mindstorms Education EV3, Class 3 Full Kit HUNA MRT3 (Russia / Korea), RoboRobo Kids (Korea), CARS CAR4 Ranger

XLinguae, Volume 11 Issue 1, January 2018, ISSN 1337-8384, eISSN 2453-711X 
(Russia), ScratchDuino (Russia) are used more often than other kits in primary education. Most robots have a lot of parts. The basic set of the most widely used in Russia LEGO WeDo has 158 parts, to assemble the models proposed by the developers it is required at least 30-50 joints of parts. In the case of insufficient experience for children in the lower grades, to assemble the model may take about 30 minutes. Of course, the creation of child's own model will take considerably more time. Few of the teachers will regularly give such amount of time for assembling the robot, so these kits can be used mainly during after-hours. Small parts of the kit can be lost, the connecting studs of plastic are quickly worn out, the designs lose their strength. Petersburg kits of the Robotic Platform and the ScratchDuino Labs (Robbo) should be taken into account here, they are assembled in a couple of minutes and can be successfully applied both in the classroom and in the after-hours activities. They are easy to assemble; line, motion, touch and light sensors included in the kit of the Robot Platform are easily connected by means of magnets; analog data is transferred to the computer; their processing and robot control is carried out in the ScratcDuino program (graphical language Scratch, there is an online version) with using the Arduino controller. Another advantage of Robbo is that programming is done using blocks in 30 languages, all the sprites and sound files of the Scratch environment have English names. This fact opens wide opportunities for using ScratxDuino robots both in English classes and in classes of groups and clubs during after-hours.

The ScratchDuino program is an augmented version of the Scratch programming environment, which allows not only to program the actions of the wheeled robot but also to create animated videos: training videos with moving and talking heroes, cartoons, interactive games, etc. Traffic sprite in ScratchDuino can be controlled using the buttons and / or the level of the Laboratory on the Arduino controller. For each background and sprite, the program compiles algorithms from command sets in English (you can switch to your native language to check the accuracy of command selection). The following command blocks (scripts) are used: Motion, Looks, Sound, Pen, Data, Events, Control, Sensing, Operators, ScratchDuino. In the Motion block, you can use commands to control the movement of the sprite on a screen such as a turn, move, go to, glide, set X, change Y, and others. In the Looks block, verbs are used that allow you to change the appearance, costumes of the sprites: say, think, show, hide, etc. It should be noted that not only pre-installed pictures can be used as a sprite, but any vector graphic image, incl. image of letters, words, etc. Scripts in the Pen section allow you to draw lines on the screen. The program has the ability to reproduce the pre-set sounds of animals (bird, dog, duck, horse, meow, owl, rooster, wolf howl), effects (car passing, door creak, hand clap, gong, etc.), musical fragments (beat box, birthday, dance celebrate, drum, guitar, etc.), and the ability to download any mp3 record into the program, record your own sound fragment and process it directly in this program, unlimitedly expand the arsenal of learning tools and the utility of the program. Operators list includes arithmetic operations, signs >, <, =, logical operators and, or, not, as well as a very useful command "letter 1 of 'world'" (can enter any number and word), which in combination with the command show and control command wait $1 \mathrm{sec}$ allows to see words on the screen letter by letter, you can change the order of output of letters by turning the video into the game "Anagrams", or you can have a dictionary dictation. The ask and answer commands in the Sensing block allow to create training simulators and tests.

Here is a list of topics for the English language curriculum in primary school, which can be studied with the help of ScratchDuino (Robbo), within the framework of the UMK "Schools of Russia," 


\begin{tabular}{|l|l|}
\hline 2 grade & Letters and numbers \\
Acquaintance with Robbo. Animals & Reading rules, orthograms \\
Me and my family (daily routine, shopping) & Verbs of motion, actions \\
The world of my hobbies (sports games) & Numbers \\
Transport & Imperative mood \\
Continents and countries. Country of the studied & Prepositions of the direction of \\
language (holidays, animals) & movement \\
Me and my friends (body parts) & Prepositions of the place \\
3 grade & Verbs to be, to have \\
Favorite pet & Present Simple, \\
Toys & Simple, Past Simple \\
Colors & General and special questions \\
Heroes of fairy tales & \\
London, Oxford, New York, Boston, Moscow \\
(sights, city orientation) \\
4 grade & \\
Seasons, weather, natural phenomena & \\
House, apartment, room & \\
City, village in Russia and the UK (travel) & \\
Domestic and wild animals & \\
My favorite activities & \\
Helping parents at home & \\
Fairy tales and adventures & \\
\hline
\end{tabular}

Here is an example of using the Robot Platform in the framework of the topic "City, village." The program of the 4th grade suggests schoolchildren to ask their classmates what there is near their house and answer such a question. Taking into account that by the 4th-grade children already know where their classmates live, to preserve the novelty it is possible to prepare for the lesson the scheme of the urban quarter or rural area with various objects near the houses in A1-A2 format. The robot is programmable for forwarding, backward, left and right movements, control can be performed using the keyboard arrows or the ScratchDuino Lab buttons. The students are divided into pairs or groups, they choose the leader, who thinks any of the houses on the scheme, the rest find out what is next to his house with the help of questions. Each pair / group brings their robot to that house ("visit" the leader). The team, who visits the right house faster than everyone, receives a "treat." Similarly, you can organize trips to the sights of London, but already manage the movement of the sprite on the screen map, using only the buttons and the level of the Laboratory.

Young schoolchildren easily master the intuitive program ScratchDuino and by the 3rd or 4th grade can develop their own games and educational projects with the robot at the lessons and after-hours activities.

\section{Using the Robots and ScratchDuino Labs has several advantages, such as:}

- formation of interest to a foreign language in general, and to some certain topic;

- mastering the foreign language in the form of a game;

- integration of several disciplines of elementary school (foreign language, computer science, mathematics, technology, the world around);

- formation of subject, meta-subject and personal results of mastering the program of primary general education;

- development of practical skills to solve actual educational problems;

- making conditions for self-expression, development of imagination and creative potential of students (children like to compose stories and tales about robots, modify and decorate them),

XLinguae, Volume 11 Issue 1, January 2018, ISSN 1337-8384, eISSN 2453-711X 
- removal of the language barrier when communicating in English and psychological difficulties in public speaking;

- creation of a situation of success for all children, etc..

\section{Results and Discussions}

The research summarized the data on the project and played activity of schoolchildren during their mastering of the English language. The analysis showed that the effectiveness of the proposed methods and means of teaching was in the ability to simplify cumbersome and complex grammatical explanations for children's perception. The first stage in the formation of the whole perception of the structure that is required for learning a foreign language, the subsequent reproduction of English language constructions, and simulation of speech structures that include multileveled language information represented by lexemes, grammatical models, language categories, help to play the lexico-syntactic combinatorics in a certain situation.

In addition, it becomes possible to achieve a consistent complication of linguistic material within all thematic clusters, which in turn provides an opportunity:

- to enlarge a vocabulary;

- to master the most complex lexical constructions;

- to transfer gradually from work in the group to individual speaking;

- to increase the overall rate of speaking;

- to minimize the presence of the native language in the structure of the lesson gradually.

As a result of the research together with the students of the profiles "Primary education. Foreign Language (English)" of the Vyatka State University, we came to the conclusion that educational robotics in English classes create a favorable atmosphere of interest and cooperation, which contributes to the achievement of common goals. Participation in play projects forms a situation of success, where everyone can try himself in various roles, learn to work in a group, achieve meaningful results personally and for the whole team. It is necessary to start such work from the initial stage of school education, creating a comprehensive basis and positive motivation for continuing the study of a foreign language in a secondary school. Of course, the impact of educational robotics on the effectiveness of forming meta-subject and subject results of general education in English and extra-curricular activities requires more thorough experimental research and discussion, which at the moment is impossible to implement due to the insufficient number of classes provided by robot designers.

\section{Conclusion}

The analysis made it possible to reveal that the long-established teaching of children in the process of play activity and the design method remain relevant and effective in the case of using a contextual approach that gives the effect of language immersion. The game and project method allow to create an exciting language environment and solve the problems of low need for students in the practical application of the English language and the lack of practice in communication. The educational robotics have an even more motivational effect, providing a real physical object for playing and gaining experience in the team, as well as understanding the personal meanings of mastering the English language and realizing the system-activity approach of the Russian standard of primary general education (Decree, 2009) as a leading approach to teaching young schoolchildren. Based on the analysis of the pedagogical literature, the school program in English, the generalization of practice at Kirov schools and the ScratchDuino robotics options, the author has offered the play training program "Pirate English" and developed examples of educational situations of using educational robotics for mastering a foreign language speech in primary school. The 
use of ScratchDuino robotics as a means of teaching and developing of 6-10-year-old children seems to be a promising direction for the research.

\section{Acknowledgments}

The study was carried out with the financial support of the State Assignment of The Ministry of Education and Science of the Russian Federation "Teacher Training Technologies in a Classical University Environment," the project № 27.9412.2017/8.9.

\section{Bibliographic references}

AIDINLOU, N.A. - ALEMI, M. - FARJAMI, F. - MAKHDOUMI, M. 2014. Applications of robot assisted language learning (RALL) in language learning and teaching. In: International Journal of Language and Linguistics, vol. 2, n. 3-1, pp. 1220. ISSN 2330-0221

AITKEN, R. 2002. Teaching Tenses. Brighton: ELB Publishing. ISBN 0952280868.

ALEKSEEVA, N.S. 2013. Application of project technology in English language lessons; In: Journal Concept. Appendix 3: Modern research, vol. 1, pp. 506-510. ISSN 2304-120X.

ANDREEV, D.V. 2015. Increased motivation to study programming in young schoolchildren as part of the robotics course. In: Pedagogical Informatics, n. 1, pp. 4048. ISSN 2070-9013.

BALAKINA, N.A. 2016. Project activity as one of the forms of formation of communicative UCD in primary school. In: Bulletin of Science and Education, n. 1, pp. 65-70. ISSN 2312-8089.

BODROVA, E.V. 2014. Methods of mastering the English language by preschool children. In: Journal Discussion, vol. 4, n. 45, pp. 124-127. ISSN 2077-7639.

DECREE OF THE RUSSIA'S MINISTRY OF EDUCATION AND SCIENCE № 373. 2009. On introducing Federal State Educational Standard of Primary Education. Adopted on Oct. 6 2009. In legistation database Garant Available online: http://base.garant.ru/197127/

EFIMENKO, N.V. 2016. Theory of Language and Intercultural Communication, KSU, n. 3, pp. 38-47. ISSN 2219-8660.

EGUCHI, A. 2014. Robotics as a Learning Tool for Educational Transformation. In: Proceedings of 4th International Workshop Teaching Robotics, Teaching with Robotics \& 5th International Conference Robotics in Education. Padova (Italy) July 18, pp. 27-34. ISBN 978-88-95872-06-3.

GALUSHKIN, A.A. 2015. Education in the Field of National Information Security in the Russian Federation and Abroad. In: Journal of Computer Science, vol. 11, n. 10, 988-994. ISSN Print: 1549-3636..

GROOT DE, A. 2002. Lexical representation and lexical processing in the L2 user. In: Cook, V. Portraits of the L2 user. Second Language Acquisition. New York: Multilingual Matters UTP. ISBN 1-85359-583-7.

GROOT DE, A., COMIJS, H. 1995. Translation recognition and translation production: Comparing a new and an old tool in the study of bilingualism. In: Language Learning, vol. 45, n. 3. pp. 467-509. ISSN: 0023-8333.

HOWARTH, D. 2000. Discourse. Philadelphia, Pa.: Open University Press. ISBN 0335-20070-2.

HYUN, E. - KIM, S. - JANG, S. - PARK, S. 2008. Comparative study of effects of language education program using intelligence robot and multimedia on linguistic ability of young children. In: Proceedings of the 14th IEEE International Workshop on Robot and Human Interactive Communication, RO-MAN. Piscataway, NJ: IEEE. 187-912.

XLinguae, Volume 11 Issue 1, January 2018, ISSN 1337-8384, eISSN 2453-711X 
KISELEVA, N.A. 2015. On the implementation of the project "Language Service". In: Philological Aspect, n. 5. pp. 9-12. ISSN 2412-8953.

KOR'AGIN, A.V. - SMOLYANINOVA, N.M. (2016). Educational robotics (Lego WeDo): Collection of methodical recommendations and workshops. Moscow. ISBN 978-5-97060-382-6.

KUNBUTTAEVA, A.SH. 2017. Problems of teaching English in grade school. In: Scientific Almanac, vol. 3-2, n. 29, pp. 439-443. ISSN 2411-7609.

LEE, S. - NOH, H. - LEE, J. - LEE, K. - LEE, G. G.. 2010. Cognitive effects of robot-assisted language learning on oral skills". In: Interspeech Satellite Workshop on Second Language Studies: Acquisition, Learning, Education and Technology. Tokyo, Japan. Available online: http://www.gavo.t.u.tokyo.ac.jp/L2WS2010/papers/L2W2010_P1-11.pdf

MANSFIELD, R.S. - BUSSE, T.V. 1981. The psychology of creativity and discovery. Chicago: Nelson Hall. ISBN 0882296531.

MEZENINA, V.I. 2016. Implementation of project activities in English language lessons as a way to increase the motivation of students. In: International Journal of Humanities and Natural Sciences Publishing house Capital, vol. 1, part 6, pp. 93-95. ISSN 2500-1000.

MIROLUBOVA, A.A. 2010. (Ed.) Methods of teaching foreign languages: traditions and modernity. Obninsk: Title. ISBN 978-5-86866-524-0.

PAPERT, S. - HAREL, I. 1991. Situating constructionism. In: Constructionism, n. 36, pp. 1-11. ISSN 1868-5145.

PEREVOZCHIKOVA, L.V. 2015. Formation of meta-subject results of distance forms of extracurricular activities in the Russian language and literature. In: Perm Pedagogical Journal, n. 7. pp. 93-96. ISSN 2219-0236.

ROGOVA, G.V. - VERESHCHAGINA, I. N. 2012. Methods of teaching English at the initial stage in general education institutions. Moscow: Enlightenment. ISBN: 978-5-09-016636-2.

RUMYANTSEVA, N.B. 2006. Training of linguistically gifted students in a foreign language in conditions of additional education. $\mathrm{PhD}$ Thesis. Saint-Petersburg: University of the Ministry of Internal Affairs of Russian.

RYNDAK, V.G. - DZHENZHER, V.O. - DENISOVA, L.V. 2009. Project activity of the schoolchild in the Scratch programming environment: educational and methodological manual. Orenburg: Orenburg State Institute of Management. Available online: http://umr.rcokoit.ru/dld/metodsupport/scratch2.pdf

SAATCIOĞLU, K.T. - BORU, B. 2015. Using Educational Robotics for Students with Learning Difficulties. In: Conference ISITES papers. Valencia, Spain. pp. 21522160. ISSN 2148-7464.

SHKABARA, I.E. - RAPYGINA, V.I. 2016. Implementation of an individual approach to teaching English. In: Conference papers Prospects for the development of science and education, Moscow. pp. 28-31. ISBN 978-5-9906984-9-9.

SINEBRYUKHOVA, V.L. - MAMEDOVA, A.T. 2015. Development of the educational motivation of young schoolchildren for technical activities by means of educational robotics. In: Concept, Special Issue, n. 17, ART 75233. ISSN 2304-120X. SULLIVAN, A. - BERS, M.U. 2015. Robotics in the early childhood classroom: learning outcomes from an 8-week robotics curriculum in pre-kindergarten through second grade. In: International Journal of Technology and Design Education, n. 10798. ISSN 1573-1804.

TANNEN, D. 1993. Framing In Discourse. Oxford: Oxford University Press. ISBN 0195079965.

TUZIKOVA, I.V. 2013. Studying robotics is the way to engineering professions. In: School and production, n. 5, pp. 45-47. ISSN 0037-4024.

ULLMANN, S. 1967. The Principles of Semantics. Oxford and Glasgow: Basil Blackwell \& Jackson \& Co. ISBN 0631054707. 
VOZLOMITEL, M.B. 2016. Forms of working with children in teaching English language. In: Master journal, vol. 12-2, n. 63, pp. 65-66. ISSN 2223-4047.

YANIKOVA, N.V. 2015. Project tasks in robotics. Available online: http://robot.edu54.ru/publications/60

Words:6161

Characters:40 752 (22,64 standard pages)

Assoc. Prof. Vera A. Rozhina, PhD

Department of Pedagogics and Methods of Pre-School and Primary Education, Vyatka State University

198 Lenin Street

610000 Kirov

Russia

va_rozhina@vyatsu.ru

Assoc. Prof. Tatiana A. Baklashova, PhD,

Institute of Psychology and Education

Kazan (Volga region) Federal University

18 Kremlyovskaya Str.

420008 Kazan

Russia

ptatyana2011@mail.ru 